\title{
RELATIONSHIP BETWEEN FAMILY SUPPORT AND SELF MOTIVATION WITH COMPLIANCE IN TAKING MEDICATION IN PATIENTS WITH TUBERCULOSIS
}

Made Mahaguna Putra ${ }^{1}$, Ni Made Yuni Dwica Astriani ${ }^{1}$, Komang Gde Trisna Purwantara ${ }^{1}$, Made Mernadi ${ }^{1}$, Putu Indah Sintya Dewi ${ }^{1}$

Afiliasi

1. Sekolah Tinggi Ilmu Kesehatan Buleleng

Dikirim 22 Agustus 2019

Direvisi 7 Juli 2020

Diterima 21 Agustus 2020

Dipublikasikan 30 November 2020

*Corresponding author

Email :

md.mahagunaputra@gmail.com

\begin{abstract}
ABSTRAK
TBC merupakan salah satu penyakit yang menyababkan kematian terbesar di dunia. TBC merupakan penyakit menular yang bisa disembuhkan tetapi butuh pegaobatan yang panjang. Salah satu faktor yang berhubungan dengan kepatuhan penderita TBC dalam pengobatan salah satunnya adalah dukungan keluarga dan motivasi diri. Tujuan penelitian ini adalah untuk mengetahui hubungan dukungan keluarga dan motivasi diri dengan kepatuhan minum obat penderita TBC di Puskesmas Sawan I. Penelitian ini merupakan penelitian korelasi dengan rancangan crosscectional. Sampel yang digunakan sebanyak 53 sampel yang dipilih secara nonprobability sampling dengan teknik purposive sampling. Data yang diperoleh diuji dengan uji Spearman Rank. Dari uji correlation dengan uji Rank Spearman diperoleh nilai p value 0,000 yang artinya ada hubungan yang signifikan antara dukungan keluarga dan motivasi diri dengan kepatuhan minum obat penderita TBC di Puskesmas Sawan I. Nilai coefficient correlation menunjukkan nilai 0,545 yang artinya adanya hubungan positif dengan kekuatan sedang. Dapat disimpulkan bahwa semakin baik dukungan keluarga dan motivasi diri penderita TBC maka semakin patuh penderita TBC dalam pengobatan.
\end{abstract}

Kata Kunci : Dukungan Keluarga, Motivasi Diri, Kepatuhan Minum Obat, Penderita TBC

\begin{abstract}
Tuberculosis is one of the diseases that causes the biggest death in the world. TB is a contagious disease that can be cured but requires a long treatment. One of the factors related to TB patient compliance in the treatment of one is family support and selfmotivation. The purpose of this study was to determine the relationship between family support and self-motivation with medication adherence for TB sufferers in the Sawan I Community Health Center. This study was a correlation study with a cross-sectional design. There are 53 respondents selected by nonprobability sampling with a purposive sampling technique. The data were analized with the Spearman rank test and the result was significant relationship ( $p$ value 0.000) and coefficient correlation was 0,545 which means it have positive relationship. It means there was a significant relationship between family support and self-motivation to medication adherence for TB patients at the Sawan I Community Health Center. In conclusion the better the family support and self-motivation of TB patients, the more obedient TB patients in treatment.
\end{abstract}

Keywords: Family Support, Self Motivation, Compliance with Taking Medication, Patients with $T B$

Sitasi jurnal :

Putra MM, Mernadi M, Purwantara KGT .2020. Relationship Between Family Support And Self Motivation With Compliance In Taking Medication In Patients With Tuberculosis. Jurnal Ilmu Keperawatan 8(2): 108-112. Doi: 10.21776/ub.jik.2020.008.02.7 


\section{PENDAHULUAN}

Penyakit tuberculosis (TBC) merupakan penyakit menular yang telah lama dikenal masyarakat sejak 2 abad terakhir. Walaupun demikian, sebagian besar negaranegara di dunia belum berhasil mengendalikan penyakit tuberculosis paru. Angka kesakitan dan kematian akibat penyakit tuberculosis paru cenderung menetap dan meningkat setiap tahunnya (Widoyono, 2011).

Menurut laporan Global Tuberculosis Report pada tahun 2012 terdapat 8.6 juta kasus tuberculosis paru baru dan pada tahun 2013 naik menjadi 9 juta. Sebanyak 1.5 juta orang meninggal dan 0.4 juta diantaranya dengan HIV positif (Muhardiani, Mardjan, \& Abrori, 2015).

Di Propinsi Bali penemuan kasus BTA postif tahun 2005 dengan prevalensi rata 38,488 per 100.000 penduduk, tahun 2006 prevalensi rate mencapai 42,306 per 100.000 penduduk dan tahun 2007 prevalensi rata mencapai 41,351 per 100.000 penduduk. Kejadian TB Paru di Bali meningkat setiap tahunnya (Lanus, 2014). Di Kabupaten Buleleng jumlah seluruh penderita tuberkulosis paru sepanjang tahun 2017 sebanyak 699 orang dengan kasus penemuan baru tuberkulosis paru BTA (+) sebanyak 302 kasus. (Mahapramana, 2017).

Dukungan keluarga merupakan faktor penting dalam kepatuhan pengobatan tuberkulosis. Dukungan keluarga dalam hal ini adalah mendorong penderita untuk patuh meminum obatnya, menunjukkan simpati dan kepedulian, serta tidak menghindari penderita dari penyakitnya (Irnawati, Siagian, \& Ottay, 2016).

Seseorang yang telah terdiagnosa menderita penyakit TB Paru tentu memerlukan perawatan dari keluarga. Berdasarkan hasil penelitian Muhardiani et al, 2015 seseorang merasa bahwa dirinya menjadi bagian dari jaringan sosial jika tiap anggotanya saling mendukung. (Muhardiani et al., 2015). Selain itu dukungan sosial juga dapat meningkatkan motivasi untuk sembuh dan semakin tinggi dukungan sosial maka semakin tinggi pula motivasi diri seorang pasien TB paru. (Octaswari, 2015).

Berdasarkan studi pendahuluan pada bulan November 2018 data kunjungan penderita Tuberkulosis paru (TB) pada tahun 2018 adalah sebanyak 60 orang, dari target yang ditetapkan adalah 63 orang penderita Tuberkulosis Paru, dari 7 orang yang wawancara 3 orang tidak patuh minum obat, 4 orang patuh minum obat, dan 3 dari 7 orang memiliki motivasi yang rendah. Sebab utama kegagalan pengobatan pasien Tuberkulosis paru adalah ketidakpatuhan pasien berobat secara teratur. Salah satu menyebabkan resistensi obat anti tuberkulosis. Oleh karena itu pemantauan pasien mempunyai kendala dalam mengakses pelayanan kesehatan sehingga perilaku dalam berobat menjadi tidak teratu (Nurarif, Amin H \& Kusuma, 2015).

Berdasarkan uraian diatas dapat dilihat masih banyak pasien tuberkulosis paru yang memiliki dekungan keluarga kurang serta motivasi diri yang kurang, oleh karena itu peneliti tertarik untuk mengadakan penelitian hubungan antara dukungan keluarga dan motivasi diri dengan kepatuhan minum obat pada penderita tuberkulosis paru di wilayah kerja Puskesmas Sawan I.

\section{METODE}

Penelitian ini menggunakan jenis deskriptif kolerasional dengan rancangan yang digunakan dalam penelitian ini adalah cross sectional (Nursalam, 2014). Variabel independen adalah dukungan keluarga dan motivasi diri sedangkan variabel dependen adalah kepatuhan minum obat, alat ukur yang digunakan adalah lembar kuesioner dengan besar sampel sebanyak 53 orang. Uji statistik yang digunakan adalah uji korelasi Spearmen rank yang digunakan untuk mengetahui hubungan antara dua variabel atau lebih yang berskala ordinal (Sugiyono, 2017)

\section{HASIL}

\section{Data Karakteristik Partisipan}

Tabel 1 : Data partisipan berdasarkan usia

\begin{tabular}{|c|c|c|}
\hline Karakteristik & $\mathrm{N}=53$ & $\%$ \\
\hline \multicolumn{3}{|l|}{ Jenis Kelamin } \\
\hline Laki-laki & 31 & 58,5 \\
\hline Perempuan & 22 & 41,5 \\
\hline \multicolumn{3}{|l|}{ Usia } \\
\hline $\begin{array}{l}\text { Min }(21 \text { th }) \\
\text { Maks }(73 \text { th) } \\
\text { Mean }(49,85)\end{array}$ & & \\
\hline \multicolumn{3}{|l|}{ Pendidikan } \\
\hline SD & 16 & 30,2 \\
\hline SLTP & 27 & 50,9 \\
\hline SLTA & 7 & 13,2 \\
\hline
\end{tabular}




\begin{tabular}{lcc}
\hline Rerguruan Tinggi & 3 & 5,7 \\
\hline Pekeriaan & & \\
\hline Buruh & 15 & 28,3 \\
\hline PNS & 3 & 5,7 \\
\hline Wiraswasta & 18 & 34,0 \\
\hline Tidak Bekeria & 17 & 32,1 \\
\hline Dukungan Keluarga & & \\
\hline Tinggi & 26 & 49,1 \\
\hline Rendab & 10 & 18,9 \\
\hline Sedang & 17 & 32,0 \\
\hline Motivasi Diri & & \\
\hline Rendah & 7 & 13,2 \\
\hline Sedang & 17 & 32,1 \\
\hline Tinggi & 29 & 54.7 \\
\hline Kepatuhan minum obat & & \\
\hline Rendah & 22 & 41.5 \\
\hline Sedang & 17 & 32,1 \\
\hline Tinggi & 14 & 26,4 \\
\hline
\end{tabular}

Sumber : data primer yang diolah

Berdasarkan tabel 1. Diketahui sebagian besar responden berjenis kelamin laki-laki dan sebagian kecil berjenis kelamin perempuan. Responden dengan usia terendah adalah 21 tahun dan usia tertinggi 73 tahun. Paling banyak responden dengan pendidikan SLTP dan paling sedikit responden yang lulus perguruan tinggi. Responden terbanyak dengan pekerjaan sebagai wiraswasta dan paling sedikit bekerja sebagai PNS. Paling banyak responden dengan dukungan keluarga tinggi dan paling sedikit dengan dukungan keluarga rendah. Motivasi diri yang dimiliki responden paling banyak adalah motivasi diri tinggi dan paling sedikit adalah motivasi diri rendah. Kepatuhan minum obat yang dimiliki responden paling banyak adalah kepatuhan minum obat yang rendah dan paling sedikit adalah kepatuhan minum obat yang tinggi.

Tabel 2 : Tabulasi data silang antar variable

\begin{tabular}{lccc}
\hline Variabel & $\begin{array}{c}\text { Kepatuhan } \\
\text { Rendah }\end{array}$ & $\begin{array}{c}\text { Kepatuhan } \\
\text { Sedang }\end{array}$ & $\begin{array}{c}\text { Kepatuhan } \\
\text { Tinggi }\end{array}$ \\
\hline $\begin{array}{l}\text { Dukungan } \\
\text { Keluarga }\end{array}$ & 1 & 1 & 8 \\
\cline { 2 - 4 } Rendah & $1.9 \%$ & $1.9 \%$ & $15.1 \%$ \\
\hline $\begin{array}{l}\text { Dukungan } \\
\text { Keluarga }\end{array}$ & $11.3 \%$ & $13.2 \%$ & $7.5 \%$ \\
\cline { 2 - 4 } Sedang & & & \\
\hline $\begin{array}{l}\text { Dukungan } \\
\text { Keluarga }\end{array}$ & 2 & 9 & 15 \\
\cline { 2 - 4 } Tinggi & $28.3 \%$ & $17.0 \%$ & $3.8 \%$ \\
\hline Motivasi & 1 & 1 & 5 \\
\cline { 2 - 4 } Rendah & $1.9 \%$ & $1.9 \%$ & $9.4 \%$ \\
\hline Motivasi & 6 & 4 & 7 \\
\cline { 2 - 4 } Sedang & $11.3 \%$ & $7.5 \%$ & $23.2 \%$ \\
\hline Motivasi & 15 & 12 & 2 \\
\cline { 2 - 4 } Tinggi & $28.3 \%$ & $22.6 \%$ & $3.8 \%$ \\
\hline & & & \\
\hline
\end{tabular}

Sumber : Data Primer yang diolah
Berdasarkan tabel 2 dapat dilihat bahwa dari total 53 responden yang diteliti sebagian besar responden mempunyai dukungan keluarga tinggi dan Kepatuhan minum obat rendah. Sisanya paling sedikit yang mengalami dukungan keluarga rendah dan kepatuhan sedang. Berdasarkan tabel diatas dapat dilihat bahwa dari total 53 responden yang diteliti, bawasannya paling banyak responden mempunyai motivasi tinggi dan kepatuhan rendah. Sisanya paling sedikit yang mengalami motivasi rendah dan kepatuhan sedang.

\section{Tabel 3: Analisis Hubungan Dukungan Keluarga dan Motivasi Diri dengan Kepatuhan Minum Obat}

\begin{tabular}{ccc}
\hline \multirow{2}{*}{ Variabel } & \multicolumn{2}{c}{ Kepatuhan Minum Obat } \\
\cline { 2 - 3 } & $\mathrm{r}$ & $\mathrm{p}$ \\
\hline Dukungan Keluarga & 0,412 & 0,002 \\
\hline Motivasi Diri & 0,545 & 0,000 \\
\hline
\end{tabular}

Sumber : Data Primer yang diolah

Hasil analisa uji Spearman rank dapat dilihat dari $p$-value yaitu $(0,002)$ yang berarti $\mathrm{p}<0,05$, maka H0 ditolak dan Ha diterima, sehingga dapat disimpulkan bahwa ada hubungan signifikan yang kuat antara variabel dukungan keluarga dengan variabel kepatuhan minum obat. Corelation Coefficient 0.412 yang berarti hubungan korelasi cukup kuat dan bernilai positif yang menandakan hubungan yang searah, semakin tinggi dukungan keluarga maka kepatuhan akan semakin tinggi. Hasil analisa uji spearment rank menunjukkan p-value yaitu $(0,000)$ yang berarti $p<0,05$, maka H0 ditolak dan Ha diterima, sehingga dapat disimpulkan bahwa ada hubungan yang signifikan kuat antara variabel motivasi diri dengan variabel kepatuhan minum obat. Corelation Coefficient 0.545 yang berarti hubungan korelasi kuat dan bernilai positif yang menandakan hubungan yang searah, semakin tinggi motivasi diri maka kepatuhan akan semakin tinggi.

\section{PEMBAHASAN}

Sebagian besar responden yang mengalami tuberkulosis paru berjenis kelamin laki-laki. Sesuai dengan penelitian yang dilakukan oleh (Prasetya, 2015) dengan hasil penelitian menunjukkan bahwa sebagian besar responden berjenis kelamin lakilaki berjumlah 32 orang $(64,0 \%)$ dan sebagian kecil responden berjenis kelamin perempuan $(36,0 \%)$. hal 
ini dikarenakan kebiasaan merokok pada laki-laki. Merokok diprediksikan sebagai faktor yang signifikan menyebabkan terjadinya perbedaan proporsi jenis kelamin terhadap kejadian TB paru (Dewi, 2014).

Peneliti menemukan dari 53 responden yang diteliti sebagian besar berpendidikan SLTP yaitu sebanyak 27 orang (50.9\%) dan banyak juga responden yang meiliki latar belakang pendidikan rendah yaitu hanya berpendidikan SD yaitu sebanyak 16 orang (30.2\%). Berdasarkan penelitian yang dilakukan oleh (Noorratri, 2016) penelitian ini menunjukkan bahwa pendidikan sangat mempengaruhi pasien tuberculosis paru dalam hal pengobatan, pendidikan yang rendah merupakan faktor yang mempengaruhi ketidakpatuhan minum obat pada pasien TB paru

Berdasarkan hasil penelitian didapatkan bahwa rata- rata umur responden adalah 49.85. Hal ini menunjukkan bahwa TB Paru sebagian besar diderita oleh orang dewasa. Sesuai dengan penelitian yang dilakukan oleh (Herawati, 2015) hasil penelitian menunjukkan bahwa penyakit TB Paru banyak ditemukan pada usia yang masih produktif yaitu 1555 tahun, karena usia tersebut banyak berinteraksi atau bersosialisasi dengan orang lain atau lingkungan sekitar (Fitri Maulidia, 2014).

Sebagian besar responden dengan TB paru berasal dari kalangan pekerjaan buruh dan wiraswasta. Orang yang bekerja mempunyai beban yang tinggi, baik beban fisik maupun beban pikiran. Sejalan dengan penelitian yang dilakukan oleh (Noorratri, 2016) hasil penelitian

\section{KESIMPULAN}

Sebagian besar responden memiliki dukungan keluarga tinggi. Paling banyak responden dengan motivasi diri tinggi dan dengan kepatuhan minum obat rendah. Uji statistik menunjukkan ada hubungan

\section{DAFTAR PUSTAKA}

Dewi, G. I. (2014) Hubungan Antara Pengetahuan, Sikap Pasien dan Dukungan Keluarga dengan Kepatuhan Minum Obat Pada Pasien Tb Paru. Jurnal Kesehatan, http:// ejournal.stikestelogorejo.ac.id/index.php/ ilmukeperawatan/article/view/89. menyatakan bahwa orang yang bekerja kurang istirahat dibanding orang yang tidak bekerja. Pekerjaan juga akan mempengaruhi dari pendapatan seseorang dan orang yang berpenghasilan tinggi cenderung lebih memperhatikan kesehatannya (Rajeswari et al., 2009). Didukung penelitian yang dilakukan, Nair et al (2007) dengan hasil penelitian bahwa sebagian besar responden dengan ekonomi rendah.

Berdasarkan hasil uji analisis menggunakan uji spearmant rank didapatkan bahwa nilai $s i g<\alpha$ $(0,002<0,05)$ yang berarti dapat disimpulkan bahwa ada hubungan yang signifikan antara dukungan keluarga dengan kepatuhan minum obat pada penderita tuberkulosis paru di wilayah kerja Puskesmas Sawan I. Menurut peneliti faktor yang mempengaruhi kepatuhan pasien dalam berobat adalah dukungan sosial di antaranya adalah dukungan dari keluarga. Tugas keluarga dalam bidang kesehatan adalah melakukan perawatan kepada anggota keluarga yang sakit (Ganes, 2012).

Dari hasil penelitian ini didapatkan bahwa nilai $\operatorname{sig}<\alpha(0,000<0,05)$ yang berarti dapat disimpulkan bahwa ada hubungan yang signifikan antara motivasi diri dengan kepatuhan minum obat pada penderita tuberkulosis paru di wilayah kerja Puskesmas Sawan I. Hal ini didukung penelitian yang dilakukan oleh Prasetya, (2015) dengan hasil penelitian bahwa semakin tinggi motivasi pasien maka akan meningkatkan kepatuhan dalam berobat.

signifikan yang kuat dan searah antara variabel dukungan keluarga dengan variabel kepatuhan minum obat, dan terdapat hubungan yang signifikan kuat dan searah antara variabel motivasi diri dengan variabel kepatuhan minum obat.

Fitri Maulidia, D. (2014). Kepatuhan Minum Obat Pada Penderita Tuberkulosis di Wilayah Ciputat, Jakarta, Universitas Islam Negeri Syarif Hidayatullah.https://s3.amazonaws.com/ academia.edu.documents/35624064.

Ganes, C. (2012). The Relationship Between Perceived Family Support As Drug Consumption Controller and Self Efficacy of Tuberculosis Patients, 
Journal Psikologi. https://www.neliti.com/ publications/62877/the-relationship-betweenperceived-family-support-as-drug-consumptioncontroller

Herawati, E. (2015). Hubungan Antara Pengetahuan dengan Efikasi Diri Penderita Tuberkulosis Paru di Balai Kesehatan Paru Masyarakat Surakarta. Artikel Publikasi Ilmiah, http://eprints.ums. ac.id/40862/

Irnawati, N. M., Siagian, I. E. T., \& Ottay, R. I. (2016). Pengaruh dukungan keluarga terhadap kepatuhan minum obat pada penderita tuberkulosis di Puskesmas Motoboi Kecil Kota Kotamobagu, Jurnal Kedokteran Komunitas dan Tropik: Volume IV Nomor 1 Februari (59).

Lanus, I. N. et al. (2014). Hubungan antara Sanitasi Rumah dengan Kejadian TB Paru di Kabupaten Bangli Tahun 2012. Jurnal Kesehatan Lingkungan, 4(2), 146-151. https://doi.org/10 $.1080 / 00288306.2004 .9515060$

Mahapramana, I. G. N. (2017). Profil kesehatan buleleng.

Muhardiani, Mardjan, \& Abrori. (2015). Hubungan antara Dukungan Keluarga, Motivasi dan Stigma Lingkungan dengan Proses Kepatuhan Berobat terhadap Penderita TB Paru di Wilayah Kerja Puskesmas Gang Sehat. Jurnal Mahasiswa Penelitian Kesehatan, 2(4), 1-10.

Nair, D. M., George, A., \& Chack, K. T. (2007). Tuberculosis New Insights From Poor Urban
Patients, 12(1), 77-85. journal health policy and planning. https://academic.oup.com/heapol/ article/12/1/77/610571

Noorratri, E. (2016). Faktor Yang Mempengaruhi Efikasi Diri Pada Pasien TB Paru. Journal Ilmiah Keperawatan Dan Kesehatan Journal of Nursing and Health (JNH), 2(1), 1-7.

Nurarif, Amin H \& Kusuma, H. (2015). Asuhan Keperawatan Berdasarkan Diagnosa Medis NANDA NIC-NOC. Yogyakarta: Mediaction Jogja.

Octaswari, N. (2015). Hubungan Antara Dukungan Sosial dan Motivasi Diri Dengan KepatuhanMinum Obat Pasien Tuberkulosis Paru di $\begin{array}{lllll}R & S & U & D\end{array}$ Panembahan Senopati, http://repository. unjaya.ac.id/2682/

Prasetya, H. (2015). Hubungan Pengetahuan dan Motivasi Pasien TBC dengan Kepatuhan Berobat Pasien TBC. https://stikesmuhla.ac.id/wpcontent/uploads/33-39-Arifal-Aris.pdf

Rajeswari, R., Balasubramanian, R., Muniyandi, M., Geetharamani, S., Thresa, X., \& Venkatesan, P. (2009). Socio-economic Impact Of Tuberculosis On Patients and Family In India, 3(November 1998), 869-877.https://www.ingentaconnect. com.

Sugiyono, P. D. (2017). Statistika Untuk Penelitian. Bandung: Alfabeta.

Widoyono. (2011). PENYAKIT TROPIS Epidemiologo, Penularan, Pencegahan \& Pemberantasannya. 